JAMP: Jurnal Adminitrasi dan Manajemen Pendidikan

Volume 1 Nomor 4 Desember 2018, Hal : 333-439

Tersedia Online di http://journal2.um.ac.id/index.php/jamp/

ISSN 2615-8574 (online)

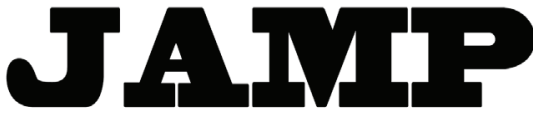

JURNAL ADMINISTRASI DAN MANAJEMEN PENDIDIKAN

\title{
BUDAYA KERJA DI SEKOLAH BERBASIS ISLAMI
}

\author{
Lupika Damai Riski \\ Burhanuddin \\ Ahmad Yusuf Sobri \\ lupikadamai26@gmail.com \\ Universitas Negeri Malang, Jalan Semarang 5, Malang 65145
}

\begin{abstract}
The purpose of the research was to describe working culture at Madrasah Tsanawiyah Assyafiyah Gondang, district of Tulungagung. This study uses a qualitative approach and uses a type of case study research. The results of the study show that there is a varied work culture in MTs Assyafiyah Gondang, district of Tulungagung, the work cultures are a culture of shaking hands between teacher and students, teacher and employee istighosah, students' guardianship, guardian culture, culture of integrity, responsibility, innovation , professional, and exemplary. In the implementation of the work culture in the madrasa there are also obstacles namely lack of time, there are teachers who are less enthusiastic in teaching, and lack of sustainability in dress. The solution that is done in overcoming these obstacles is the holding of deliberations, motivations and oral and written warnings.
\end{abstract}

Keywords: culture, working culture

\begin{abstract}
Abstrak: Tujuan penelitian ini adalah untuk mendeskripsikan budaya kerja di Madrasah Tsanawiyah Assyafiiyah Gondang, Kabupaten Tulungagung. Penelitian ini menggunakan pendekatan kualitatif dan menggunakan jenis penelitian studi kasus. Hasil penelitian menunjukkan bahwa ada budaya kerja yang bervariasi di MTs Assyafiiyah Gondang, kabupaten Tulungagung, budaya kerja adalah budaya berjabat tangan antara guru dan siswa, guru dan karyawan istighosah, perwalian siswa, budaya wali, budaya integritas, tanggung jawab, inovasi, profesional, dan patut dicontoh. Dalam pelaksanaan budaya kerja di madrasah juga ada kendala yaitu kurangnya waktu, ada guru yang kurang antusias dalam mengajar, dan kurangnya keberlanjutan dalam berpakaian. Solusi yang dilakukan dalam mengatasi kendala ini adalah mengadakan rapat dan musyawarah, motivasi dan peringatan lisan dan tertulis.
\end{abstract}

Kata Kunci: budaya, budaya kerja

Guru sebagai tenaga pendidik berperan dalam menciptakan sumber daya manusia yang berkualitas. Hal tersebut dikarenakan guru yang mendidik serta mengajar siswa di kelas yang nantinya juga akan menjadi tenaga kerja atau sumber daya manusia setelah menyelesaikan sekolahnya. Dengan kata lain guru merupakan ujung tombak dari keberhasilan pendidikan di sekolah. Guru dituntut untuk dapat bekerja secara kompeten, dengan adanya kompetensi diharapkan guru dapat melaksanakan kewajibannya dan memenuhi semua tuntutan dari kompetensi tersebut. Selain tenaga pendidik yang harus bekerja secara kompeten tenaga kependidikan juga diharuskan memiliki kompetensi yang baik dalam bekerja.

Kinerja pendidik dan tenaga kependidikan diharapkan mampu memberikan kontribusi yang maksimal supaya hasil yang akan dicapai dapat memuaskan. Kinerja pendidik serta tenaga kependidikan dapat dipengaruhi oleh beberapa faktor, salah satu faktor tersebut adalah adanya budaya atau kultur organisasi di sekolah. Budaya adalah suatu kebiasaan, cara hidup masyarakat yang berkembang dan 
dimiliki oleh sebuah kelompok orang dan diwariskan dari generasi ke generasi. Kerja adalah usaha seseorang untuk mencari nafkah. Hasibuan (2004) menyatakan bahwa kerja adalah suatu pengorbanan jas, jasmani, dan pikiran untuk menghasilkan suatu barang-barang atau jasa-jasa dengan memperoleh imbalan prestasi. Nawawi (2003) menyebutkan bahwa budaya kerja adalah kebiasaan yang dilakukan secara berulang-ulang oleh pegawai dalam suatu organisas.

Salah satu budaya dalam lingkungan organisasi atau dalam lembaga pendidikan adalah budaya kerja, budaya kerja tersebut dilaksanakan oleh seluruh guru dan tenaga kependidikan yang ada dalam organisasi tersebut. Budaya kerja guru dan tenaga kependidikan akan mempengaruhi upaya dalam pelaksanaan peningkatan kualitas pendidikan hal tersebut dikarenakan budaya kerja merupakan suatu kebiasaan kerja yang dilakukan oleh tenaga pendidik di suatu instansi. Kebiasaan-kebiasaan yang baik akan menjadikan citra sekolah serta kualitas pendidikan di sekolah tersebut baik. Selain hal tersebut budaya kerja di suatu sekolah juga mempengaruhi produktivitas kerja pendidik dan tenaga kependidikan. Budaya kerja memiliki tujuan untuk mengubah sikap dan juga perilaku guru dan tenaga kependidikan yang ada agar dapat bekerja secara baik dan produktif untuk menghadapi berbagai tantangan di masa yang akan datang, karena suatu kesinambungan organisasi sangat bergantung pada budaya yang dimiliki.

Hasil observasi di MTs Assyafiiyah Gondang Kabupaten Tulungagung menunjukkan bahwa budaya kerja yang diterapkan di MTs Assyafiiyah Gondang dapat memberikan perubahan kepada pendidik dan tenaga kependidikan, perubahan yang dimaksudkan adalah dengan adanya budaya tersebut pendidik dan tenaga kependidikan menjadi lebih termotivasi untuk bekerja, menjadi lebih memiliki rasa kekeluargaan dan juga bekerja menjadi lebih menyenangkan. Hal tersebut disampaikan oleh salah satu guru di MTs Assyafiiyah Gondang Tulungagung, guru tersebut menyatakan bahwa dengan adanya budaya kerja di madrasah seluruh guru menjadi memiliki rasa tanggung jawab, kekeluargaan kerukunan dan bekerja menjadi lebih menyenangkan.

\section{METODE}

Penelitian ini menggunakan pendekatan kualitatif hal tersebut dikarenakan penelitian ini meneliti hal atau fenomena yang unik yang terjadi di sekolah yang diteliti. Jenis penelitian yang digunakan adalah jenis penelitian studi kasus yaitu metode penelitian yang memusatkan perhatian pada suatu kasus secara intensif dan rinci, (Ulfatin, 2015: 25). Dalam penelitian ini kehadiran peneliti sangat penting, dikarenakan dalam penelitian ini peneliti merupakan pengumpul data. Sumber data utama dalam penelitian ini adalah kata-kata, tindakan dan dokumen-dokumen.

Teknik pengumpulan data dalam penelitian ini menggunakan teknik observasi, wawancara dan dokumentasi. Dalam menganalisis data terdapat beberapa aktivitas yang dilakukan yaitu data reduction, data display dan data conclusion drawing/verification. Peneliti menggunakan teknik triangulasi sumber dan triangulasi metode untuk menguji kredibitas data yang diperoleh dari pengecekan data yang telah diperoleh melalui beberapa sumber, misalnya melalui wawancara dan observasi. Tahap-tahap yang dilakukan dalam penelitian ini yaitu tahap pra penelitian, tahap pelaksanaan penelitian serta tahap pasca penelitian.

\section{HASIL}

\section{Peran Kepala Sekolah dalam Pelaksanaan dan Pengembangan Budaya Kerja Islam}

Upaya dalam mengembangkan budaya kerja di madrasah tentunya terdapat kepala madrasah yang berperan aktif di dalamnya, karena kepala madrasah selain sebagai manajer di suatu sekolah tetapi juga sebagai motivator. Dalam pengembangan dan pelaksanaan budaya kerja di MTs Assyafiiyah Gondang Tulungagung, disiplin dalam bekerja sangat diterapkan dan diperhatikan, jika ada guru yang tidak mematuhi peraturan yang ada akan ditindak dengan tegas. 
Selain beberapa hal diatas salah satu bentuk dan peran kepala sekolah dalam mengembangkan budaya kerja Islam di MTs Assyafiiyah Gondang Tulungagung yaitu dengan diadakannya kegiatankegiatan seperti kegiatan mengaji. Kegiatan mengaji bersama antara siswa dan guru tersebut dilakukan pada hari selasa, rabu, kamis dan juga sabtu. Kegiatan tersebut dilakukan jam ke-0 dijam pertama.

Kegiatan tersebut dilakukan sebagai upaya dalam meningkatkan serta mengembangkan budaya kerja di sekolah berbasis Islam MTs Assyafiiyah Gondang Tulungagung. Gambar 1.1 di bawah ini merupakan bagan peran kepala sekolah dalam pelaksanaan serta pengembangan budaya kerja.

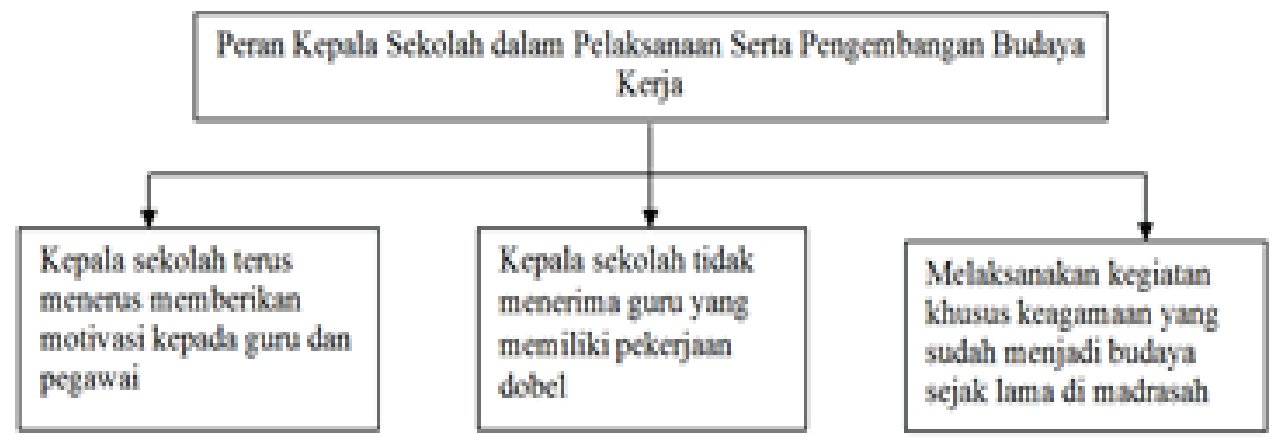

Gambar 1 Bagan Peran Kepala Sekolah dalam Pelaksanaan Serta Pengembangan Budaya Kerja Islam.

\section{Implementasi Pelaksanaan Budaya Kerja di Sekolah Berbasis Islam MTs Assyafiiyah Gondang Kabupaten Tulungagung}

Implementasi budaya kerja di sekolah berbasis Islam MTs Assyafiiyah Gondang Tulungagung yaitu terdapat berbagai macam kegiatan yang ada dan telah menjadi budaya serta cirikhas dari MTs tersebut. Budaya kerja tersebut di antaranya adalah (a) pembiasaan berjabat tangan guru dan siswa; (b) istighosah guru dan pegawai; (c) istighosah peserta didik dan walinya; (d) budaya berbusana; (e) budaya integritas, profesinal, inovasi, tanggung jawab dan budaya keteladanan.

Budaya-budaya kerja tersebut diatas adalah merupakan budaya kerja dan cirikhas yang dimiliki oleh MTs Assyafiiyah Gondang Tulungagung, budaya kerja tersebut dikembangkan dan terus dilaksanakan oleh setiap guru dan pegawai. Budaya kerja guru dan pegawai juga terkait dengan budaya peserta didik disekolah. Karena kegiatan yang dilaksanakan oleh peserta didik dan melibatkan guru tentunya menjadi budaya kerja bagi guru di MTs Assyafiiyah Gondang Tulungagung.

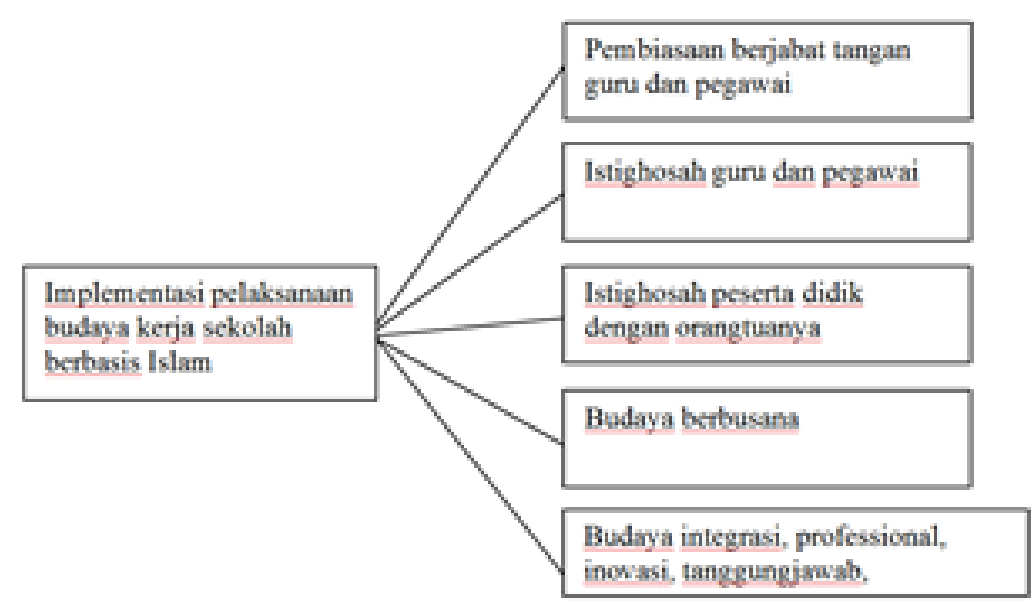

Gambar 2 Bagan Implementasi Pelaksanaan Budaya Kerja Sekolah.

\section{Hambatan yang Dialami oleh Pendidik dalam Menerapkan Budaya Kerja di Sekolah Berbasis Islam MTs Assyafiiyah Gondang Tulungagung}

Hambatan yang terjadi dalam pelaksanaan budaya kerja di MTs Assyafiiyah Gondang Kabupaten Tulungagung yaitu kurangnya waktu dalam pelaksanaan budaya kerja tersebut, masih terdapat beberapa 
guru yang kurang antusias dalam mengajar, kurangnya kesinambungan dalam hal berbusana, setiap guru dan tenaga kependidikan memiliki tupoksinya masing-masing sehingga tidak ada waktu dalam melaksanakan budaya kerja tersebut. Berikut gambar bagan 1.3 tentang hambatan budaya kerja di MTs Assyafiiyah Gondang Tulungagung.

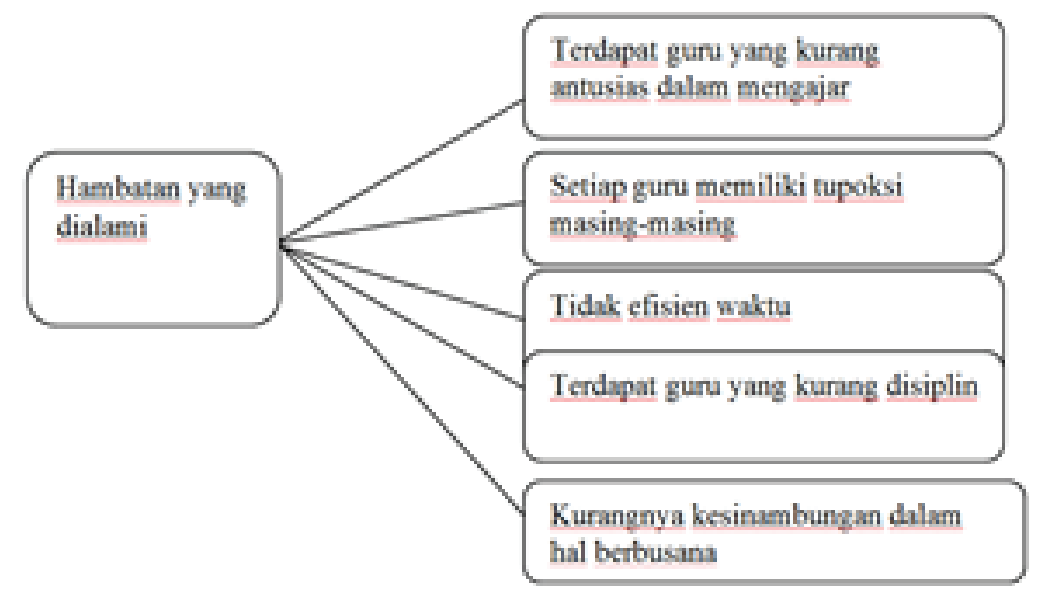

Gambar 3 Bagan Hambatan yang Dialami dalam Menerapkan Budaya Kerja

\section{Solusi yang Dilakukan untuk Menanggulangi Hambatan-Hambatan yang Dialami}

Solusi yang dilakukan untuk menanggapi hambatan-hambatan yang terjadi tidak lepas dari peran seorang kepala madrasah. Dalam menanggulangi hambatan tersebut kepala MTs Assyafiiyah Gondang Tulungagung salah satunya berperan sebagai motivator, kepala madrasah memberikan motivasi-motivasi terhadap guru dan tenaga kependidikan yang telah melanggar tersebut. Setelah itu kepala madrasah mengadakan rapat dan musyawarah untuk menyelesaikan masalah tersebut.

Selain itu kepala madrasah juga memberikan sanksi lisan dan juga tertulis, contoh dari sanksi tertulis tersebut adalah pemberian Surat Peringatan (SP), SP tersebut terdiri dari tiga yaitu SP1, SP2, dan SP3. Namun apabila guru atau tenaga kependidikan tersebut tetap tidak ada etikat untuk berubah dan mentaati peraturan maka guru atau tenaga kependidikan yang melanggar tersebut akan diberikan sanksi tegas yaitu dinonaktifkan dari madrasah tersebut. Berikut gambar 1.4 tentang solusi dari hambatan yang dialami tersebut.

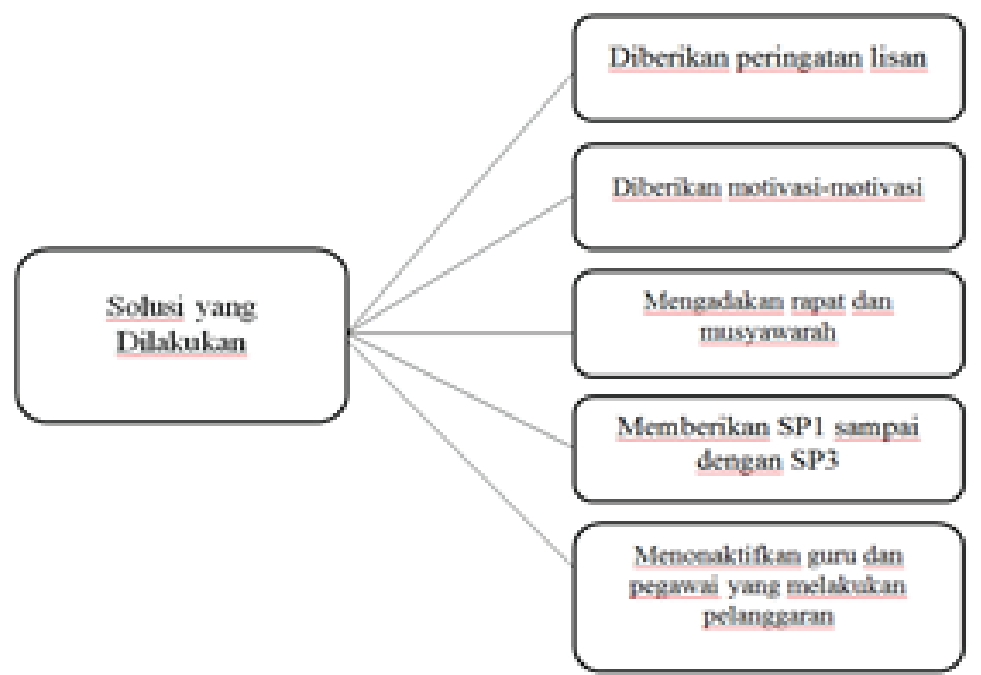

Gambar 4 Bagan Solusi yang Dilakukan untuk Menanggulangi Hambatan- Hambatan yang Dialami 


\section{PEMBAHASAN}

\section{Peran Kepala Sekolah dalam Pelaksanaan dan Pengembangan Budaya Kerja Islam}

Hasil temuan penelitian, dalam pelaksanaan dan pengembangan budaya kerja Islam di MTs Assyafiiyah Gondang Tulungagung adalah dengan menerapkan dan memperhatikan adanya disiplin dalam bekerja di lingkungan madrasah. Upaya kepala sekolah dalam pelaksanaan serta mengembangkan budaya kerja di MTs Assyafiiyah sudah dilakukan misalnya dengan terus memberikan motivasi, memberikan contoh agar terus meningkatkan budaya kerja yang telah ada di MTs Assyafiiyah Gondang Tulungagung. Motivasi sangat diperlukan karena dengan adanya motivasi akan mempengaruhi kebiasaan serta menumbuhkan semangat para guru dalam melaksanakan budaya kerja di MTs Assyafiiyah Gondang Tulungagung. Sesuai dengan pendapat Dominika (2001) bahwa seorang kepala sekolah dalam pelaksanaan tugasnya memiliki beberapa fungsi atau peran penting, yakni sebagai pemimpin, pendidik, manajer, supervisor, inovator dan motivator. Selain itu juga menurut Susanto (2015) menyatakan bahwa kepala sekolah adalah sebagai motor penggerak peningkatankinerja guru dituntut untuk memiliki visi, misi dan wawasan yang luas. Kepala sekolah sebagai motivator diharapkan memiliki strategi dalam memberikan motivasi kepada para guru dan tenaga kependidikan di sekolah. Motivasi tersebut dapat ditumbuhkan melalui lingkungan kerja, suasana kerja dan disiplin dalam bekerja.

\section{Implementasi Pelaksanaan Budaya Kerja di Sekolah Berbasis Islam MTs Assyafiiyah Gondang Kabupaten Tulungagung}

Temuan peneliti pada implementasi pelaksanaan budaya kerja disekolah berbasis Islam adalah terdapat berbagai macam budaya kerja yang diterapkan di MTs Assyafiiyah Gondang Tulungagung tersebut, budaya kerja yang ada di MTs tersebut adalah sebagai berikut: (a) pembiasaan berjabat guru dan peserta didik; (b) istighosah guru dan tenaga kependidikan (c) istighosah peserta didik dan walinya; (d) budaya berbusana; (e) budaya integritas, profesional, tanggungjawab, inovasi, dan keteladanan.

Hasil temuan tersebut sesuai dengan pendapat-pendapat para ahli yaitu Supriyadi dan Guno (2006), yang menyebutkan bahwa yang dimaksud dengan nilai-nilai budaya kerja dalam pedoman antara lain adalah (a) komitmen dan konsisten terhadap visi, misi dan tujuan organisasi, dalam pelaksanaan kebijakan Negara serta perarturan yang telah berlaku; (b) wewenang dan tanggungjawab; (c) keikhlasan dan kejujuran; (d) integritas dan professional; (e) kreativitas dan kepekaan terhadap lingkungan tugas; (f) kepemimpinan dan keteladanan; (g) kebersamaan dan dinamika kelompok kerja; (h) keberanian dan kearifan dalam mengambil keputusan dan konflik; (i) semangat dan motivasi; (j) ketekunan dan kesabaran; (k) keadilan dan keterbukaan dan (1) penguasaan ilmu dan teknologi. Menurut Kanwil (2017) lima nilai budaya kerja yang diterapkan di jajaran Kementrian Agama RI saat ini dijiwai oleh spirit, emosional spiritua selain itu nilai budaya kerja yang dimaksud yaitu integritas, profesional, tanggung jawab, inovasi dan keteladanan. Kelima nilai tersebut menjadi acuan bersama setiap pegawai di Kemenag, mulai dari atasan hingga bawahan. Menurut Setyaningrum (2016) menyatakan bahwa seluruh guru dalam menjalankan profesinya diharapkan mampu menjadi tauladan bagi kemajuan suatu madrasah atau sekolah sesuai dengan lima budaya kerja yaitu integritas, profesional, tanggungjawab, inovasi, dan keteladanan.

\section{Hambatan yang Dialami oleh Pendidik dalam Menerapkan Budaya Kerja di Sekolah Berbasis Islam MTs Assyafiiyah Gondang Tulungagung}

Hasil temuan penelitian hambatan yang dialami oleh pendidik dalam menerapkan budaya kerja tersebut adalah kurangnya waktu, karena setiap guru dan pegawai memiliki tupoksinya masing-masing sehingga terkadang sibuk untuk mengerjakan kegiatannya masing-masing. Selain itu kendala yang terjadi yaitu terdapat guru atau pegawai yang kurang disiplin, kurangnya kesinambungan antar guru dan 
pegawai. Hal tersebut tentunya menjadi kendala dalam mewujudkan pelaksanaan budaya kerja yang optimal dan baik dalam suatu lembaga organisasi.

Hal tersebut sesuai dengan teori dan pendapat dari para ahli menurut Nurhadijah (2017) bahwa salah satu penghambat adanya budaya kerja disekolah adalah disiplin dalam bekerja adalah kurangnya kesinambungan antar guru serta adanya masalah pribadi antar guru serta kurangnya kerjasama yang baik antar guru dan pegawai. Selain teori tersebut diatas terdapat teori pendukung yang dikemukakan oleh Lutfi (2007), salah satu hambatan dalam pelaksanaan budaya kerja adalah terkait nilai professional guru dalam bekerja, menurut Lutfi masih terdapat guru yang memiliki kebiasaan sering datang terlambat, tidak masuk kerja tanpa izin, tidak tepat waktu dan tidak disiplin dalam mengajar, serta masih terdapat guru yang merangkap dalam pelaksanaan tugasnya. Menurut Srisinto (2015) menyatakan bahwa hambatan budaya di lingkungan kerja salah satunya yaitu karena kurangnya profresional dalam melaksanakan pekerjaan serta tanggung jawab profesinya.

\section{Solusi yang Dilakukan untuk Menanggulangi Hambatan-Hambatan yang Dialami}

Temuan peneliti tentang alternatif yang dilakukan untuk menanggulangi hambatan yang dialami dalam menerapakan budaya kerja di sekolah adalah Ibu kepala madrasah tidak harus setiap hari memonitoring karena para guru telah dianggap mengerti dan memiliki rasa tanggungjawab dalam bekerja. Tetapi jika terdapat guru yang masih belum dapat untuk mematuhi peraturan yang ada, maka guru tersebut akan diberikan SP 1, SP 2, SP 3 sampai dengan penonaktifan kerja.

Hal tersebut sesuai dengan teori yang telah dikemukakan oleh Suparjati (2000) pemberian Surat Peringatan atau (SP) ditujukan kepada individu yang berbuat dan melanggar sesuatu yang telah disepakati bersama. Selain teori diatas teori pendukung lainnya adalah menurut Peraturan Pemerintah Republik Indonesia Nomor 53 Tahun 2010 Bab III bagian kedua tentang Tingkat dan Jenis Hukuman Disiplin Pasal 7 adalah salah satu jenis hukuman terhadap PNS yang melanggar disiplin secara ringan adalah dengan memberikan teguran lisan, teguran tertulis yang dimaksud adalah pemberian surat peringatan, dan pernyataan tidak puas dengan kinerja secara tertulis. Menurut Srisinto (2015) menyatakan bahwa hambatan-hambatan dari pelaksanaan budaya tersebut dapat ditanggulangi dengan adanya motivasi, motivasi tersebut dapat diperoleh dari atasan dan juga dari diri para pegawai itu sendiri.

\section{KESIMPULAN}

Berdasarkan hasil penelitian dapat ditarik kesimpulan: (1) Peran kepala madrasah dalam pelaksanaan serta pengembangan budaya kerja Islam sangat penting dikarenakan kepala sekolah merupakan manajer, supervisor dan inovator. Kepala madrasah juga merupakan tolok ukur keberhasilan suatu lembaga pendidikan atau sekolah. Dalam mengembangkan budaya kerja di MTs Assyafiiyah Gondang kepala sekolah melaksanakan pembiasaan serta budaya yang telah ada untuk terus menerus dilaksanakan dan dikembangkan. Kepala madrasah juga menerapkan disiplin kerja yang kuat bagi para guru dan tenaga kependidikan . Kepala madrasah MTs Assyafiiyah gondang dalam mengembangkan budaya kerja yang baik dan secara Islam beliau tidak menerima guru yang memiliki dua tanggungan pekerjaan dari sekolah satu ke sekolah yang lain, karena menurut beliau hal seperti itu sangat berpengaruh pada konsistensi dalam bekerja, dalam bekerja pasti nantinya akan ada yang diberatkan; (2) Implementasi budaya kerja Islam di MTs Assyafiiyah Gondang terdapat beberapa budaya kerja diantaranya adalah (a) pembiasaaan berjabat tangan guru dan siswa (b) istighosah bapak ibu guru dan pegawai (c) budaya pelaksanaan isthigosah peserta didik dengan walinya setiap tahun (d) budaya berbusana (e) budaya integrasi, professional, inovasi, tanggungjawab dan keteladanan; (3) Ada beberapa kendala yang dialami oleh guru dalam melaksanakan budaya kerja di MTs Assyafiiyah Gondang Tulungagung. Kendala tersebut adalah satunya adalah tidak efien waktu, karena setiap guru dan pegawai memiliki tupoksinya masingmasing sehingga terkadang sibuk untuk mengerjakan budaya kerja yang ada, terdapat guru yang kurang disiplin dalam mengajar, terdapat kurangnya kesinambungan dalam hal berbusana; (4) Tindak lanjut serta alternatif tersebut yaitu bagi guru yang melanggar dan tidak melaksanakan budaya kerja yang ada 
dengan baik akan diberikan motivasi, mengadakan rapat dan musyawarah, memberikan pengarahan, memberikan peringatan tertulis berupa SP1, SP2 dan SP3, namun jika tetap tidak berubah maka akan segera dinonaktifkan. Karena hal tersebut jika dibiarkan ditakutkan akan membawa dampak negatif dan juga berpengaruh terhadap pelaksanaan budaya kerja di sekolah berbasis Islam MTs Assyafiiyah Gondang Tulungagung.

\section{DAFTAR RUJUKAN}

Dominika, N. 2001. Peran Kepala Sekolah dalam Pengembangan Budaya Kualitas Kerja Bagi Guru dan Karyawan Sekolah. Dinamika Pendidikan No 2: 99.

Hasibuan. 2004. Manajemen Sumber Daya Manusia, Ed Revisi. Jakarta: PT Bumi Aksara.

Kanwil. 2017. Menjiwai Lima Budaya Kerja Kementrian Agama RI, (online), (https://kalsel.kemenag.go.id/ berita/503601/KaKanwil-ESQ-Menjiwai-5-Nilai-Budaya-Kerja-Kementerian-Agama), diakses pada 7 Agustus 2018.

Lutfi. 2007. Hambatan Budaya Kerja Para Guru. Online (https://paknewulan.wordpress.com), diakses pada 2 Mei 2018.

Nawawi, H. 2003. Manajemen Sumber Daya Manusia untuk Bisnis yang Kompetitif. Yogyakarta: Gadjah Mada University Press

Nurhadijah. 2017. Studi Tentang Budaya Kerja Pegawai Sekolah Menengah Kejuruan Negeri 1 Penajam Paser Utara. e-journal Administrasi Negara, I (5): 5476-5489.

Setyaningrum. 2016. Lima Nilai Budaya Kerja Kementrian Agama, (online), (http://teraju.id/opini/lima-nilaibudaya-kerja-kemenag-1660/), diakses pada 7 Agustus 2018.

Supriyadi \& Guno, T. 2006. Budaya Kerja Organisasi Pemerintah (Modul Pendidikan Dan Pelatihan Prajabatan Golongan I dan II). Jakarta: Lembaga Administrasi Negara Republik Indonesia.

Susanto, H. 2015. Tugas dan Peran Kepala Sekolah, (online), (https://bagawanabiyasa.wordpress.com/2015/12/03/ tugas-dan-peran-kepala-sekolah), diakses pada 7 Agustus 2018.

Srisinto. 2015. Tinjauan Kasus Budaya Kerja Organisasi Pemerintah Menilik Budaya Kerja Pegawai Negeri Sipil, (online), (http://pusdiklat.bps.go.id/index.php?r=artikel/view\&id=329), diakses pada 7 Agustus 2018.

Suparjati. 2000. Surat Menyurat dalam Perkantoran. Yogyakarta: Kanisius.

Ulfatin, N. 2015. Metode Penelitian Kualitatif di Bidang Pendidikan: Teori dan Aplikasinya. Malang: Bayumedia Publishing. 